\title{
Critical Deposition Condition of CoNiCrAlY Cold Spray Based on Particle Deformation Behavior
}

\author{
Yuji Ichikawa $^{1} \cdot$ Kazuhiro Ogawa ${ }^{1}$
}

Submitted: 16 December 2015/in revised form: 11 October 2016/Published online: 9 December 2016

(C) The Author(s) 2016. This article is published with open access at Springerlink.com

\begin{abstract}
Previous research has demonstrated deposition of MCrAlY coating via the cold spray process; however, the deposition mechanism of cold spraying has not been clearly explained—only empirically described by impact velocity. The purpose of this study was to elucidate the critical deposit condition. Microscale experimental measurements of individual particle deposit dimensions were incorporated with numerical simulation to investigate particle deformation behavior. Dimensional parameters were determined from scanning electron microscopy analysis of focused ion beam-fabricated cross sections of deposited particles to describe the deposition threshold. From Johnson-Cook finite element method simulation results, there is a direct correlation between the dimensional parameters and the impact velocity. Therefore, the critical velocity can describe the deposition threshold. Moreover, the maximum equivalent plastic strain is also strongly dependent on the impact velocity. Thus, the threshold condition required for particle deposition can instead be represented by the equivalent plastic strain of the particle and substrate. For particle-substrate combinations of similar materials, the substrate is more difficult to deform. Thus, this study establishes that the dominant factor of particle deposition in the cold spray process is the maximum equivalent plastic strain of the substrate, which occurs during impact and deformation.
\end{abstract}

Keywords cold spray $\cdot$ deposition mechanism $\cdot$ FIB

Yuji Ichikawa

ichikawa@rift.mech.tohoku.ac.jp

1 Fracture and Reliability Research Institute, Tohoku University, Sendai, Japan

\section{Introduction}

The cold spray process-a relatively new coating technology — was initially developed in the mid-1980s at the Institute for Theoretical and Applied Mechanics of the Siberian Division of the Russian Academy of Science in Novosibirsk (Ref 1-4). This technique is based on the highvelocity $(300-1200 \mathrm{~m} / \mathrm{s})$ impingement of small solid particles (generally $1-50 \mu \mathrm{m}$ in diameter) on the substrate (Ref $3,4)$. In this spraying process, the particles are accelerated by a supersonic gas jet at the heated gas temperature, which is usually lower than the melting point of the powder material. Consequently, this spraying process solved the problems of thermal spraying, i.e., oxidation and phase transformation (Ref 5, 6). Moreover, cold spraying systems are much simpler than low-pressure plasma spray (LPPS) systems.

MCrAlY (where M is Co and/or Ni) is widely used for the bond-coat of thermal barrier coating (TBC) for landbased gas turbine applications. Additionally, MCrAlY is used for protection from high-temperature oxidation and hot corrosion (Ref 7, 8). Until recently, MCrAlY has been deposited by conventional thermal spray techniques, i.e., LPPS or high velocity oxygen fuel (HVOF).

Recently, researchers have demonstrated the deposition of MCrAlY coatings via the cold spray process (Ref 9, 10). Moreover, the coating performance with this process is much higher than for conventional coating (Ref 11). In order to commercialize the cold spray coating process, the deposition mechanism, optimal deposition parameter, and coating reliability must be understood.

From previous cold-sprayed MCrAlY coating research results, there is no evidence of local melting near the deposition interface (Ref 12); thus, local melting is not necessary for high-quality deposition. Scanning electron 
microscopy (SEM) and electron backscatter diffraction (EBSD) microstructural analysis of cold-sprayed copper deposits indicate that highly plastic deformations cause grain refinement and amorphous structure generation (Ref 13). Furthermore, in the initial stage of MCrAlY cold spray deposition, surface-covering oxide films can roll to inhibit particle attachment (Ref 14). This evidence indicates that the deposition mechanism may be considered as follows. (1) Dynamic impacts cause large plastic deformation of particle and substrate. The deformation causes grain refining. (2) The brittle native oxide film is broken by the large deformation; non-protected and active surfaces of the particle and substrate are generated. (3) Contact between both sides of the newly formed surfaces initiates deposition by cold spraying. Therefore, the generation of the newly formed surface is the dominant factor for deposition due to cold spraying.

Various explanations for the deposition mechanism have been studied, and many concepts have been proposed (Ref 15-17). The critical velocity for deposition is one of the most important factors for understanding the deposition mechanisms of cold spraying. Only when the impact velocity exceeds, the critical velocity can cold spraying initiate deposition. Assadi et al. (Ref 18) have investigated the critical velocity and deposition mechanism through experimental and computational approaches. If plastic deformation of the particle and substrate occurs, highspeed friction causes shear stress. Subsequently, the friction induces increments in temperature. This model assumes that a local area exceeds the melting point owing to high-speed collisions between particles and substrate; however, this is contrary to the aforementioned evidence that bonding occurs without melting. This result also indicates that the thickness of the oxide film is a factor that affects deposition (Ref 17). Therefore, it is necessary to discuss dominant factors other than temperature change.

Accordingly, this study focuses on particle deformation as the dominant factor of cold spray deposition. The plastic deformation rate increases with impact velocity; hence, the generated area of newly formed surface also increases. The amount of plastic deformation, namely, the generated amount of newly formed surface, is used for the evaluation parameter of deposition. Initially, as an experimental approach, a specimen with sparsely deposited particles was prepared. Observation of the cross sections of particles attached to the substrate efficaciously elucidates their deformation behavior. In this study, a focused ion beam (FIB) system was used to fabricate the cross section of a deposited particle in microscale (Ref 19, 20). Furthermore, finite element method (FEM) simulation can determine the relationship between deformation behavior and impact conditions (Ref 21-24). Therefore, FEM results were incorporated with the observation results. By comparing these experimental and computational results, the dominant factor of cold spray deposition was studied.

\section{Experimental Procedure}

\section{Cold Spraying for Preparation of Sparse Particle Deposition}

CoNiCrAlY (Sulzer Metco, AMDRY9951) was used as a coating material. Ni-based superalloy Inconel 625 , with dimensions of $50 \mathrm{~mm} \times 50 \mathrm{~mm} \times 4 \mathrm{~mm}$ was used as the substrate. The chemical compositions of the powder and substrate materials are shown in Tables 1 and 2, respectively. In order to capture and evaluate the deformation of individual particles, the substrate was mirror polished. The CoNiCrAlY coatings were sprayed using a cold-spray facility (Kinetic 3000, CGT). The spray conditions adopted match those shown in the table for the previous research (Ref 15). Figure 1 shows the x-ray powder diffraction (XRD) patterns of the feedstock CoNiCrAlY powder and as-sprayed coating. The as-sprayed coating result has a wider peak, which confirms grain miniaturization of the cold-sprayed coating.

Particle deformation behavior was investigated by using a sparsely deposited particles specimen, which was made with a small powder supply and higher traverse speed. Table 3 summarizes the cold spray condition. Using this spray condition for single traverse spraying, a specimen with sparsely and individually deposited particles was obtained. Figure 2 shows the appearance of the specimen.

\section{Cross-Sectional Observation of Deposited Particle Fabricated via FIB System}

The FIB system (Hitachi, FB-2000A) was used to fabricate the cross section of a deposited particle. The FIB is capable of pinpoint analysis and extremely precise cutting on the order of a few nanometers. Figure 3 depicts the FIB fabricated specimen. This image was produced by SEM at a

Table 1 Chemical composition of powder material (CoNiCrAlY)

\begin{tabular}{lccccc}
\hline Element & Co & $\mathrm{Ni}$ & $\mathrm{Cr}$ & $\mathrm{Al}$ & $\mathrm{Y}$ \\
\hline wt.\% & Bal. & 32 & 21 & 8 & 0.5 \\
\hline
\end{tabular}

Table 2 Chemical composition of substrate material (Ni-based superalloy)

\begin{tabular}{lccccc}
\hline Element & $\mathrm{Ni}$ & $\mathrm{Cr}$ & $\mathrm{Mo}$ & $\mathrm{Nb}$ & $\mathrm{Fe}$ \\
\hline wt.\% & Bal. & 21 & 9 & 4 & 3.5 \\
\hline
\end{tabular}




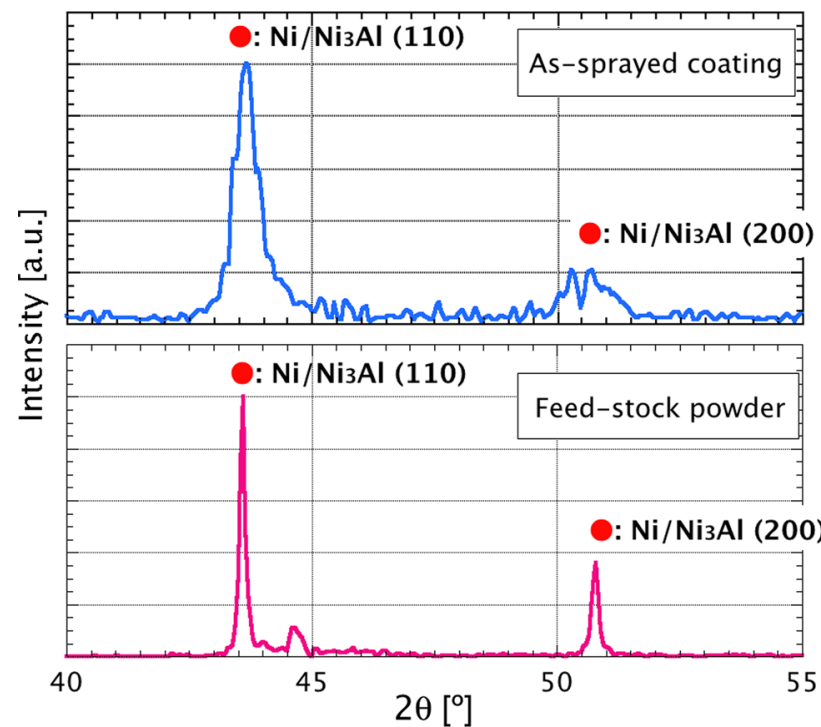

Fig. 1 XRD patterns of feedstock and as-sprayed CoNiCrAlY powder obtained with copper $\mathrm{x}$-ay source under $40 \mathrm{kV} / 30 \mathrm{~mA}$

Table 3 Cold spray conditions for fabrication of sparsely deposited particles specimen

\begin{tabular}{ll}
\hline Material & AMDRY 9951 CoNiCrAlY \\
\hline Facility & CGT KINETHICS 3000 \\
Gas & Nitrogen \\
Gas pressure & $3 \mathrm{MPa}$ \\
Gas temperature & $600{ }^{\circ} \mathrm{C}$ \\
\hline
\end{tabular}

$45^{\circ}$ oblique direction. The interface between the deposited particle and substrate is visible in this image.

\section{Dimensional Evaluation Method for Particle Deformation Behavior}

In order to evaluate the deformation behavior of the deposition particles, experimental and simulation approaches were applied. The dimensions of deposited particles were measured from cross-sectional SEM images. Furthermore, these measurement results were compared with FEM simulation results. Because the individual particle diameters are not identical, a normalized characterization is required for the investigation. From previous research, deposits are of higher quality when the particle and substrate are both significantly deformed. Therefore, vertical deformation is a key parameter for describing both deformations. In order to normalize the incursion depth to the initial particle diameter, the measured incursion depth $(D)$ was divided by the width $(W)$ and height $(H)$ of the particle. In this measurement, dimension parameters, such

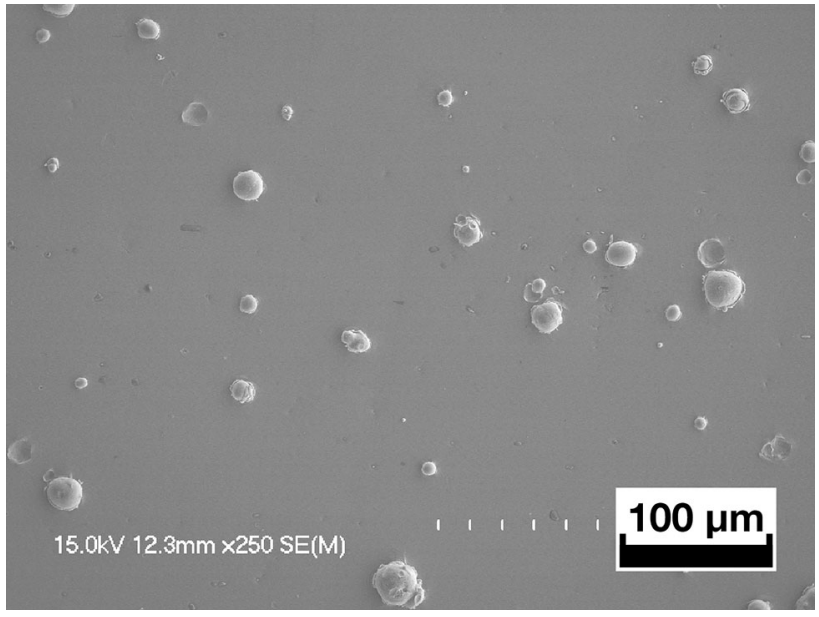

Fig. 2 SEM image of sparsely deposited particles specimen

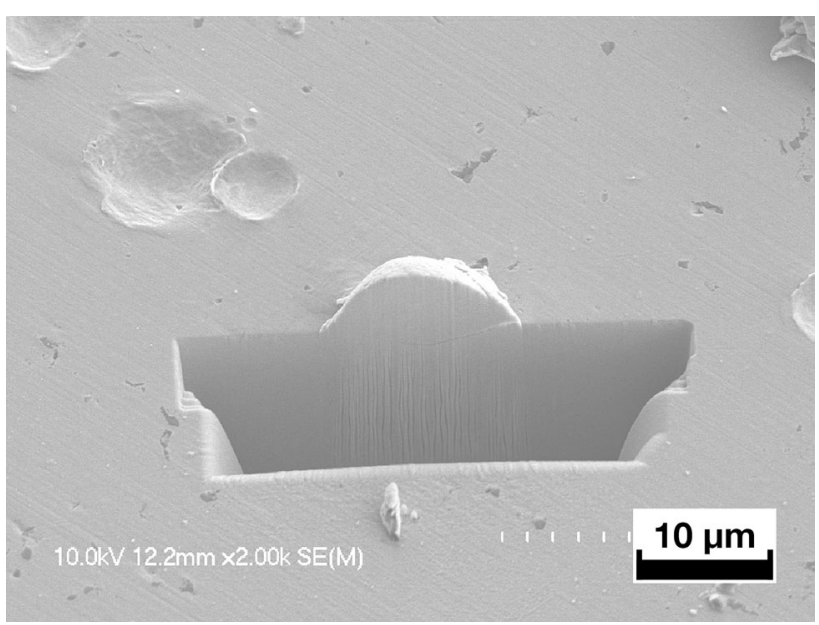

Fig. 3 Example of FIB-cut deposited particle

as the width, height, and incursion depth, of the substrate are defined as in Fig. 4. Finally, the ratios $D / W$ and $D /$ $H$ were used for evaluation. Since the obtained SEM images were observed from $45^{\circ}$ angles, the obtained SEM images were compressed in a vertical direction. Consequently, to evaluate the dimensional parameter, vertical measurements from the image were scaled by the square root of two.

\section{FEM Simulation for Deformation Behavior}

In order to estimate the stress and strain for a deposited particle and substrate, a Johnson-Cook (J-C) simulation (Ref 25-27) was performed. The J-C model is an empirically based representation of the flow stress defined as:

$$
\begin{aligned}
\sigma= & {\left[A+B\left(\varepsilon_{\mathrm{p}}\right)^{n}\right]\left[1+C \ln \left(\dot{\varepsilon}_{\mathrm{p}} / \dot{\varepsilon}_{\mathrm{p} 0}\right)\right] } \\
& \times\left[1-\left(T-T_{R}\right)^{m} /\left(T_{\mathrm{M}}-T_{\mathrm{R}}\right)^{m}\right],
\end{aligned}
$$


where $\sigma$ is the flow stress, $\varepsilon_{\mathrm{p}}$ is the equivalent plastic strain, $\dot{\varepsilon}_{\mathrm{p}}$ is the equivalent plastic strain-rate, $T$ is the temperature, $\dot{\varepsilon}_{\mathrm{p} 0}$ is the reference plastic strain-rate, $T_{\mathrm{M}}$ is the melting temperature, $T_{\mathrm{R}}$ is the reference temperature, $n$ is the strainhardening exponent, and $A, B, C$, and $m$ are constants. The $\mathrm{J}-\mathrm{C}$ simulation requires knowledge of the material constants; however, it is difficult to obtain the actual material constants of Inconel 625 and AMDRY 9951. Some researchers have studied the mechanical properties of $\mathrm{Ni}$ based superalloys such as Inconel 718 (Ref 28-30). The mechanical properties of some $\mathrm{Ni}$ - and Co-based alloys are shown in Table 4 (Ref 28-30). From the table, it can be seen that the mechanical properties of these alloys do not differ greatly; therefore, this study uses the material constants of Inconel 718 for the impact simulation. Table 5 shows the parameters used in the J-C model, which were obtained by Sievert et al. (Ref 28). The FEM model and conditions are summarized in Fig. 5 and Table 6, respectively.

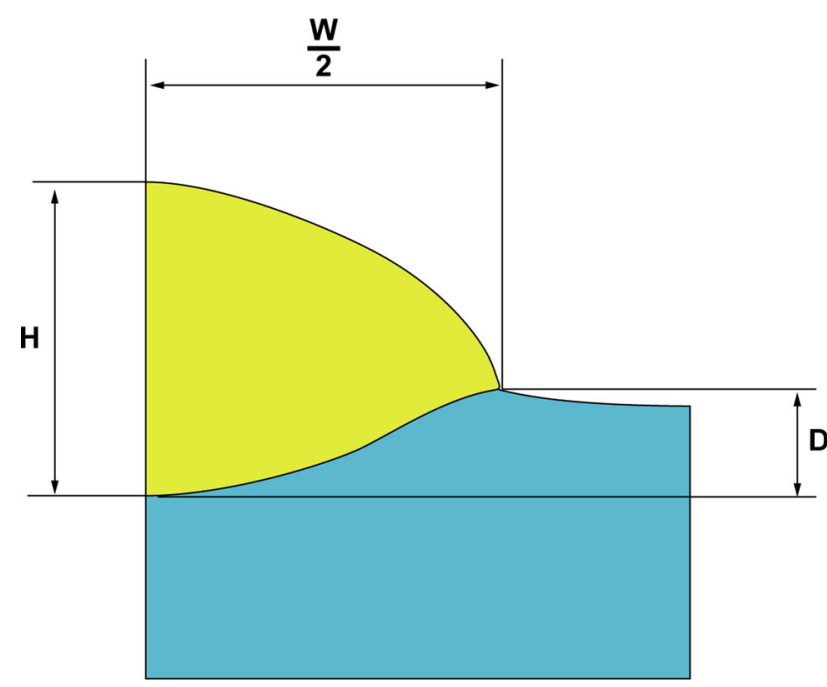

Fig. 4 Definition of dimensional evaluation parameters in crosssectional particle observation ( $H$ height; $W$ width; $D$ incursion depth of deposited particle)

\section{Results and Discussion}

\section{Experimental Characterization of Deposited Particle}

Each deposited particle has a different diameter and different impinging conditions. Therefore, it is necessary to evaluate the adhesion deformation behavior of individual particles. Figure 6 shows an example of particle observation: the particle is semi-bonded. The particle did not impact the substrate in a perfectly perpendicular direction during the cold spraying. Based on the relationship

Table 5 Johnson-Cook parameters of Inconel 718 (Ref 29)

\begin{tabular}{lccccccc}
\hline$A(\mathrm{MPa})$ & $B(\mathrm{MPa})$ & $C$ & $m$ & $n$ & $\begin{array}{c}\dot{\varepsilon}_{\mathrm{p} 0}(1 / \\
\mathrm{s})\end{array}$ & $\begin{array}{c}T_{\mathrm{R}} \\
\left({ }^{\circ} \mathrm{C}\right)\end{array}$ & $\begin{array}{c}T_{\mathrm{M}} \\
\left({ }^{\circ} \mathrm{C}\right)\end{array}$ \\
\hline 450 & 1700 & 0.017 & 1.3 & 0.65 & $10^{-3}$ & 25 & 1297 \\
\hline
\end{tabular}

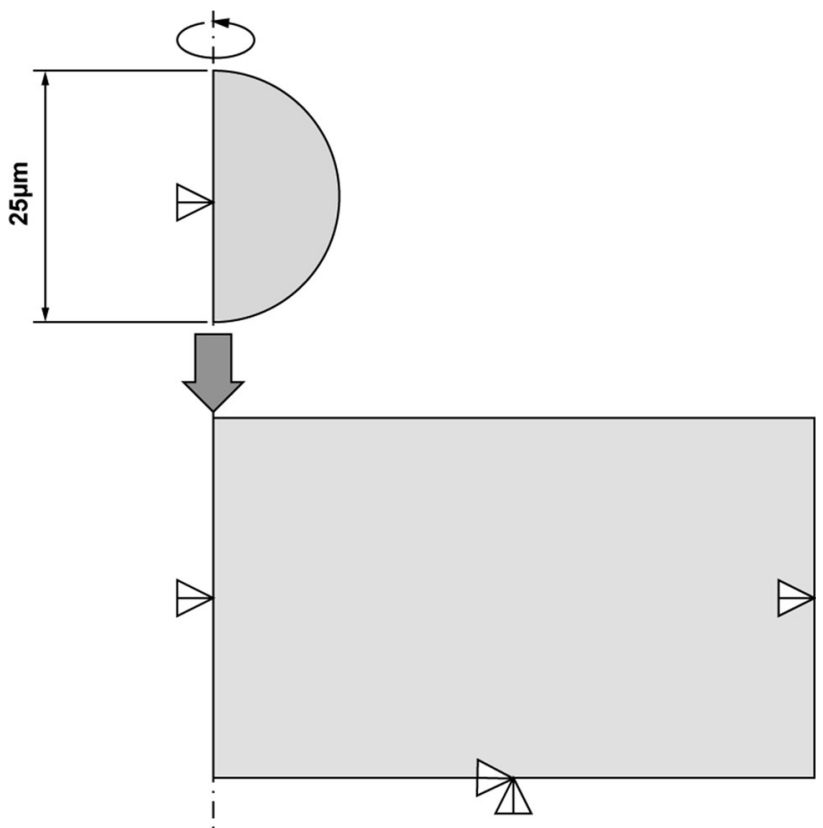

Fig. 5 Schematics of FEM impact simulation model

Table 4 Mechanical properties of Ni- and Co-based alloys (under room temperature conditions) (Ref 28-30)

\begin{tabular}{lcccc}
\hline & Yield strength $(\mathrm{MPa})$ & Tensile strength $(\mathrm{MPa})$ & Elongation $(\%)$ & Hardness \\
\hline $\begin{array}{l}\text { Co-based superalloy } \\
\text { Udimet 188 }\end{array}$ & 446 & 963 & 55 & $\ldots$ \\
$\begin{array}{l}\text { Ni-based superalloy } \\
\text { Inconel 625 }\end{array}$ & 414 & 827 & 60 & $175-240 \mathrm{HB}(185-250 \mathrm{Hv})$ \\
$\begin{array}{l}\text { Ni-based superalloy } \\
\text { Inconel } 718\end{array}$ & 448 & 896 & 54 & $95 \mathrm{Rb}(220 \mathrm{Hv})$ \\
\hline
\end{tabular}


Table 6 FEM simulation conditions

\begin{tabular}{ll}
\hline Software & ABAQUS / CAE Ver. 6.5-3 \\
Modeling space & $\begin{array}{l}\text { Axial symmetric model } \\
\text { Temperature displacement } \\
\text { Element type }\end{array}$ \\
& $25 \mu \mathrm{m}$ \\
Particle diameter & $0.5 \mu \mathrm{m}$ \\
Mesh size & Adaptive mesh \\
Re-mesh & $873 \mathrm{~K}$ \\
Particle initial temperature & $300 \mathrm{~K}$ \\
Substrate initial temperature & Young's modulus \\
Elastic deformation model & Johnson-Cook \\
Plastic deformation model & 0.9 \\
Inelastic fever heat &
\end{tabular}

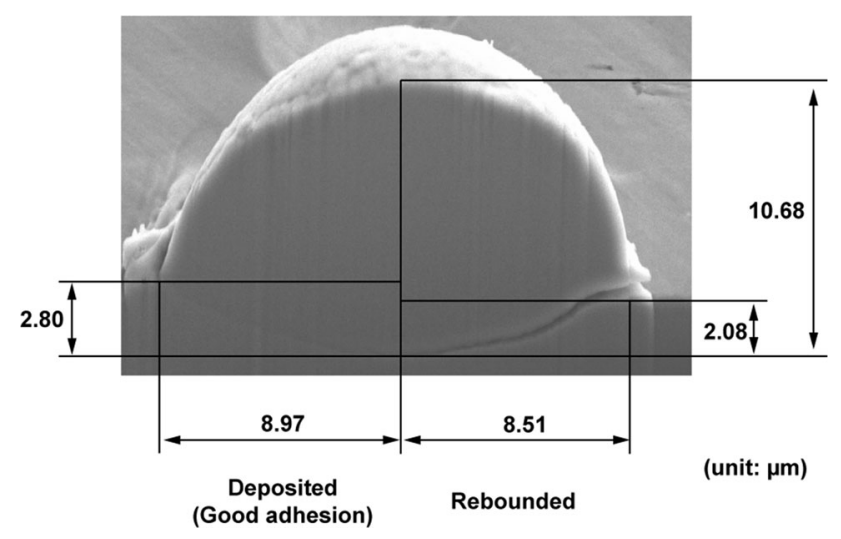

Fig. 6 Measurement example of half-deposited particle. This single particle displays two deposit conditions: its left side has been well deposited; its right side has rebounded. These differences are caused by the impact angle and different deformation rates

between the deposited particle and nozzle position, this particle may have impinged from the upper right corner of this image. Consequently, the deformation of the left half of the particle was larger than that of the right-the left part was well deposited, but the right was not. Therefore, it was possible to investigate and obtain dimensional parameters of these two different conditions from this one image. Table 7 presents the two-dimensional parameters obtained from the particle in Fig. 6.

This process was performed for similar cross-sectional observations of more than 10 semi-bonded particles. The measured dimensional parameters, i.e., the intrusion depth/ width and intrusion depth/height, are summarized in Fig. 7 and 8 , respectively.

The triangle marks in these plots represent the ratios of non-deposited particles, and the circle marks represent those of particles with good adhesion. In both plots, there is a clear threshold range between the dimensional parameters of the deposited and rebounded (non-deposited) particles. The deposited particles are more deeply deformed in
Table 7 Example measurement results of dimensional parameters of the semi-deposited particle (Fig. 6)

\begin{tabular}{ccc}
\hline & Deposited & Rebounded \\
\hline$D / W$ & 0.624 & 0.488 \\
$D / H$ & 0.262 & 0.195 \\
\hline
\end{tabular}

the perpendicular direction; therefore, the deposit threshold is determined by the deformation volume of the particle and substrate.

\section{Simulation Approach to Explain the Deformation Behavior and Deposition Threshold}

In this simulation, the particle size is $25 \mu \mathrm{m}$ in diameter and the initial temperature is $600{ }^{\circ} \mathrm{C}$. In this experiment, the initial temperature of nitrogen gas is $600{ }^{\circ} \mathrm{C}$, which is identical to the temperature of the pre-chamber of the cold spray system. Therefore, the actual gas temperature and particle temperature at impact is expected to be lower than $600{ }^{\circ} \mathrm{C}$. In the present simulation, the relationship between deformation behavior and impact velocity is considered, as the temperature of impact particles is not an effective parameter because it affects only the mechanical properties of the particles and substrate. Further, the material system is suitable for use in high-temperature environments, and the changes in mechanical properties are not significant at a temperature of $600{ }^{\circ} \mathrm{C}$ or less. To understand the deformation behavior, a temperature of $600{ }^{\circ} \mathrm{C}$ was adopted in this study, which is the most severe condition in the experiment.

Figure 9 shows the FEM simulation results for the strain and temperature distribution for particles impinging at various impact velocities. The strain and temperature distributions show nearly the same tendency, for highly deformed regions have higher temperature increases. However, previous research results indicate that melting at the interface is not the necessary conditions for deposition (Ref 15). Moreover, surface activation bonding and other room temperature bonding techniques allow each metal to bond without temperature increase (Ref 30). Considering these results, the temperature rise and heat transfer at the interface is not the key factor for deposition; however, strain can reasonably be discussed as the dominant factor.

Noting that the contact interface of the particles and the substrate does not substantially deform at the central region for any impact velocity, the greatest deformation occurs along the edge of the contact surface. This large deformed region may contribute to bonding; however, it cannot be evaluated by employing the mean value of the plastic deformation of the interface. Therefore, the maximum value of equivalent plastic strain was used as the evaluation parameter. 


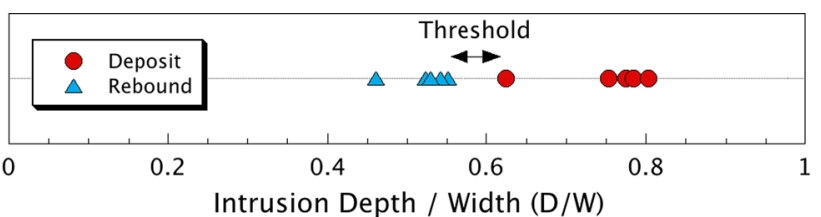

Fig. 7 Relationship between particle deposition behavior and dimensional parameter $D / W$

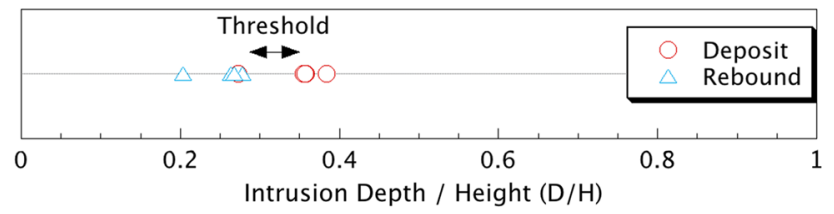

Fig. 8 Relationship between particle deposition behavior and dimensional parameter $\mathrm{D} / \mathrm{H}$

The dependency of the maximum equivalent plastic strain on impact velocity is shown in Fig. 10. The highest value of the maximum equivalent plastic strain occurred at an impact velocity of $500 \mathrm{~m} / \mathrm{s}$. Furthermore, for velocities over $600 \mathrm{~m} / \mathrm{s}$, the maximum equivalent plastic strain decreased. From the simulation results of the deformed particle and substrate shown in Fig. 9, for impact velocities of 600 and $700 \mathrm{~m} / \mathrm{s}$, the edge shape after deformation had a much steeper angle. Moreover, a strong constraint condition caused a reduction in the maximum strain values. Despite the low strain values, these particles have a very large deformation. Conversely, the maximum strain of the substrate monotonically increased with the velocity. Especially in the case of 500 and $600 \mathrm{~m} / \mathrm{s}$, a rapid rise in maximum strain was observed. A similar rapid increase was observed from 300 to $500 \mathrm{~m} / \mathrm{s}$. These tendencies indicate that the substrate was more difficult to deform than the particles.

Figure 11 shows the relationships between the dimensional parameters and impact velocity, which were obtained from the FEM results in Fig. 10. These results indicate that the ratio of the intrusion depth and width and the ratio of the intrusion depth and height increase linearly with the velocity. The linear approximation formulas shown in Fig. 11 are as follows:

$V_{\mathrm{d} 25-\mathrm{DW}}=(D / W+0.243) / 0.00137$,

$V_{\mathrm{d} 25-\mathrm{DH}}=(D / H+0.216) / 0.00090$,

where $V_{\mathrm{d} 25-\mathrm{DW}}$ and $V_{\mathrm{d} 25-\mathrm{DH}}$ are the impact velocities calculated from the intrusion depth/width ratio and the intrusion depth/height ratio, respectively, for particles with diameters of $25 \mu \mathrm{m}$.

Figure 12 shows velocities obtained for the experimental results from Fig. 7 and 8 using the approximate relationships in Eq 2 and 3. Using these equations, the threshold velocity is obtained; the threshold velocity range is given for the two parameters in Table 8. Consequently, the critical impact velocity for good adherence lies in the range of $576-629 \mathrm{~m} / \mathrm{s}$. From these discussions of the critical velocity, it is possible to redefine the method of deformation.

\section{Why Strain is the Dominant Factor of Deposition}

A prior research (Ref 15) indicated that the deposition mechanism of cold spraying required the creation of new surfaces and high-pressure contact between the particle and substrate, as shown in Fig. 13. Previous observation results obtained using transmission electron microscopy (TEM) indicate that particle melting cannot be observed at the interface (Ref 15). In other words, the amount of newly created surface depends on the amount of plastic deformation. In particular, the complex deformation behavior can be explained using equivalent plastic strain. Hence, the essential requirement for deposition is described by the necessary and sufficient amount of the equivalent plastic strain of the particle and substrate. Figure 10 shows the relationship between the equivalent plastic strain and impact velocity. The result indicates that the equivalent plastic strain of the particles is always larger than that of the substrate. It can be observed that the particles are easy to deform. When the impact velocity of a particle is higher than $500 \mathrm{~m} / \mathrm{s}$, the equivalent plastic strain of the particle is reduced. Because the particles are significantly deformed in the vertical as well as the transverse directions, the absolute amount of deformation is considered to increase as the equivalent plastic strain decreases.

The cold spray deposition mechanism is fundamentally related to the strains of the substrate and particle. In order to discuss the equivalent plastic strain, the relationship between the critical speed conditions obtained from the deformed shape and simulation needs to be clarified. Figure 14 shows the estimated threshold velocity results with respect to the relationship between the maximum values of the equivalent plastic strain and impact velocity in Fig. 10. The threshold strain can be estimated from the intersection of the threshold velocity and the maximum equivalent plastic strains. The critical velocity ranges between 576 and $629 \mathrm{~m} / \mathrm{s}$. At this velocity range, the equivalent plastic strain of the particles ranges from 550 to $600 \%$ and that of the substrate ranges from 175 to $200 \%$. The required particle impact velocity to obtain an equivalent plastic strain of $550 \%$ for the particles is $500 \mathrm{~m} / \mathrm{s}$. Furthermore, considering that plastically deforming the substrate is much more difficult, the minimum amount of equivalent plastic strain necessary for the bonding of this material system can be considered to range between 170 and $200 \%$. Hence, the essential requirement for deposition is described by the 


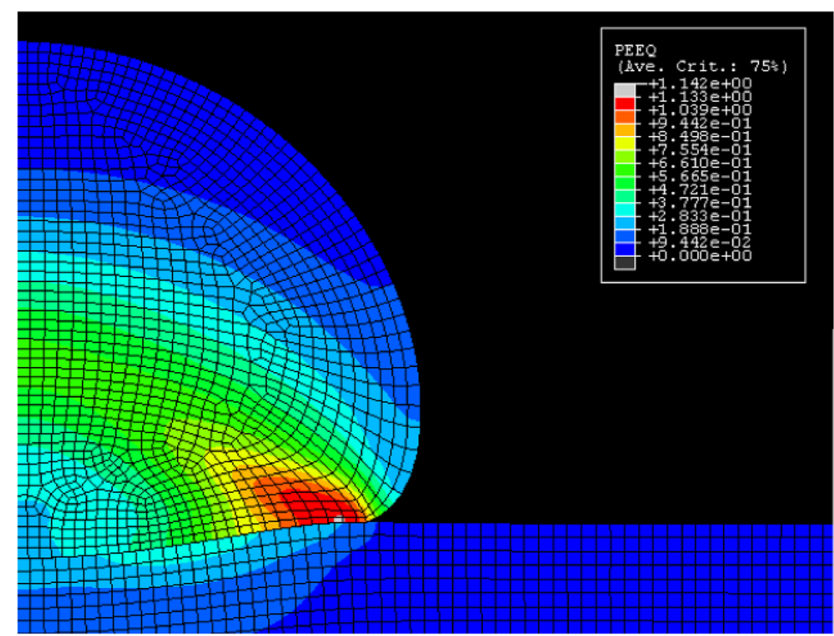

(a)

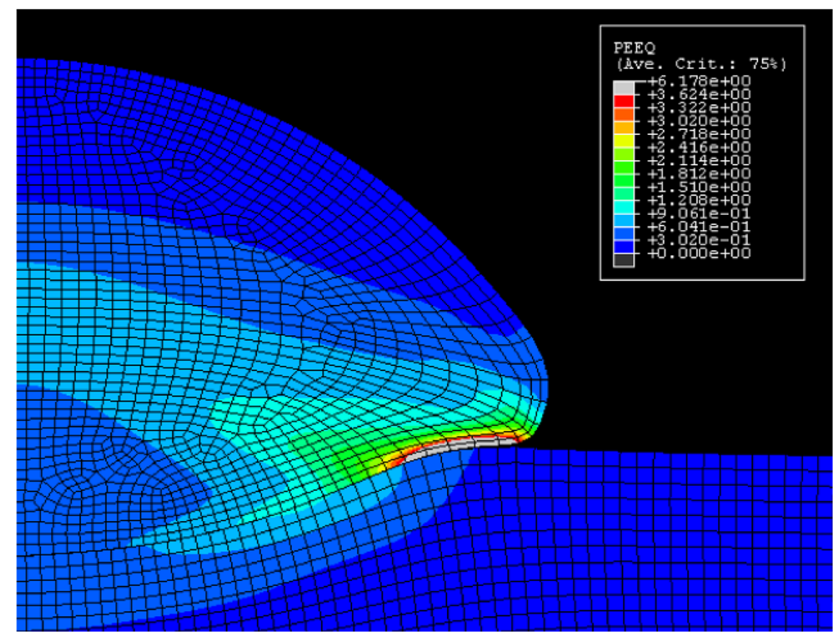

(b)

Equivalent Plastic Strain

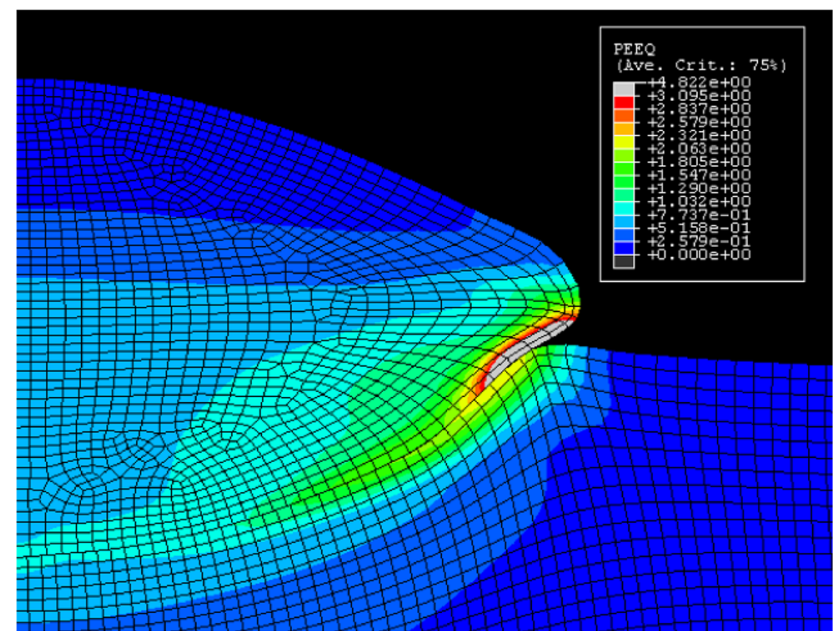

(c)

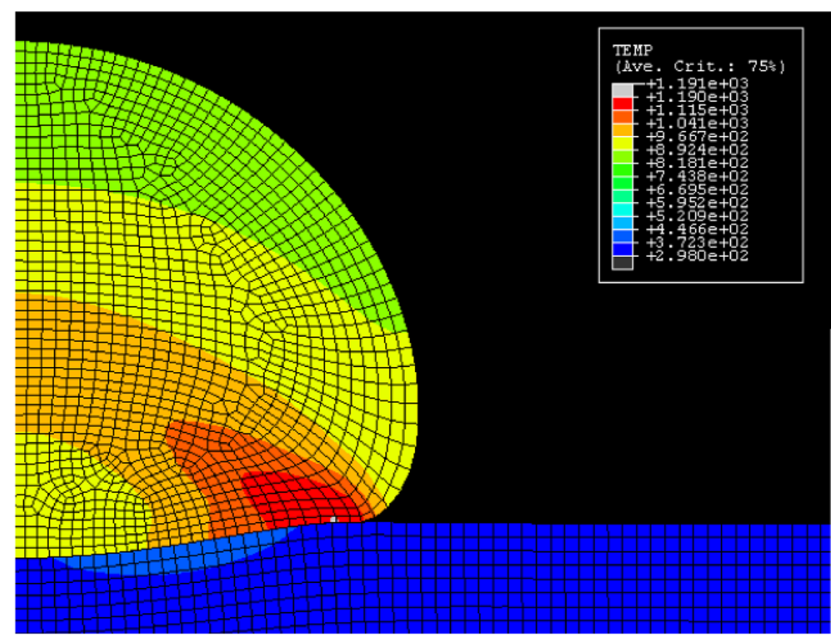

Temperature

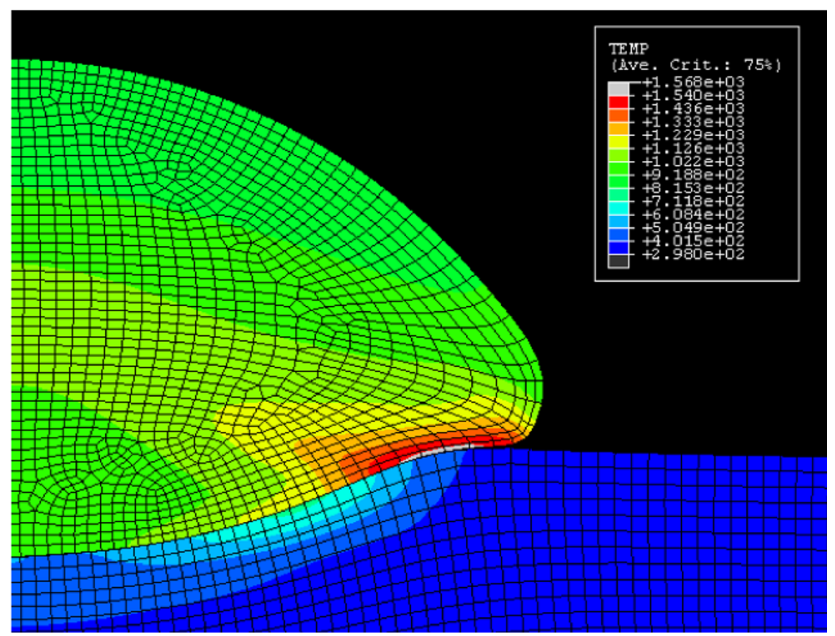

Temperature

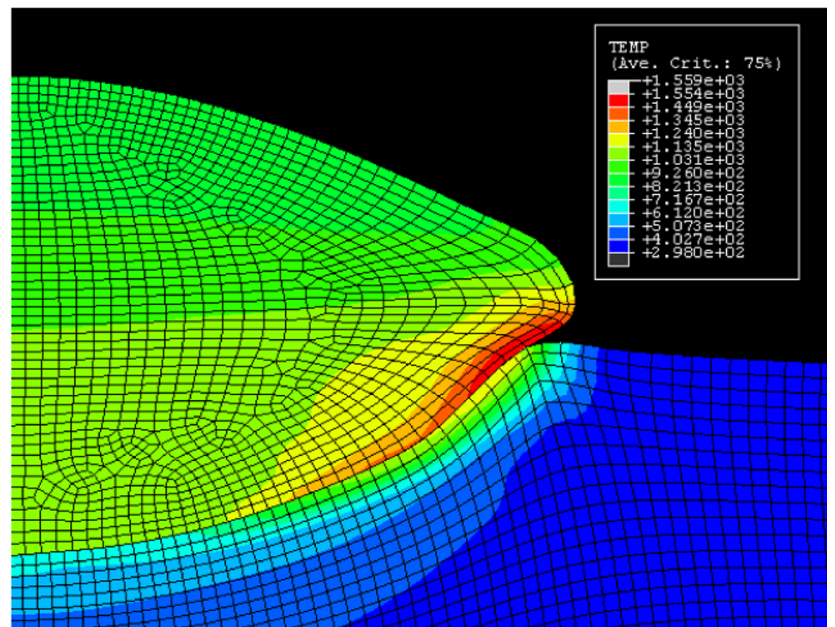

Temperature

Fig. 9 FEM simulation results of equivalent plastic strain and temperature distribution in maximum deformed state of impinging particle and substrate for various impact velocities 


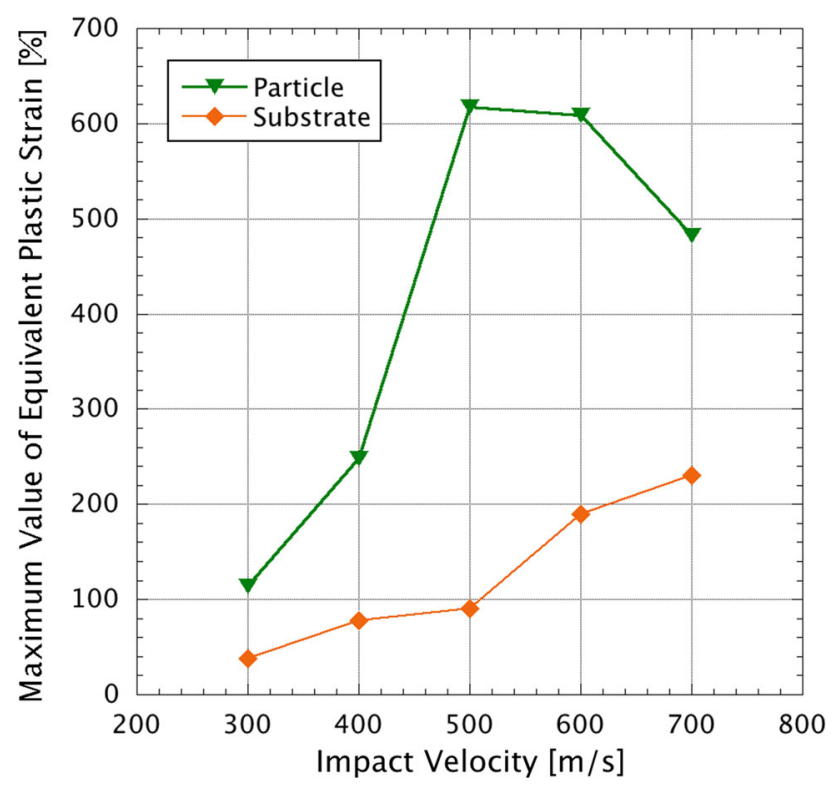

Fig. 10 Relationship between maximum strain and impact velocity of particle and substrate

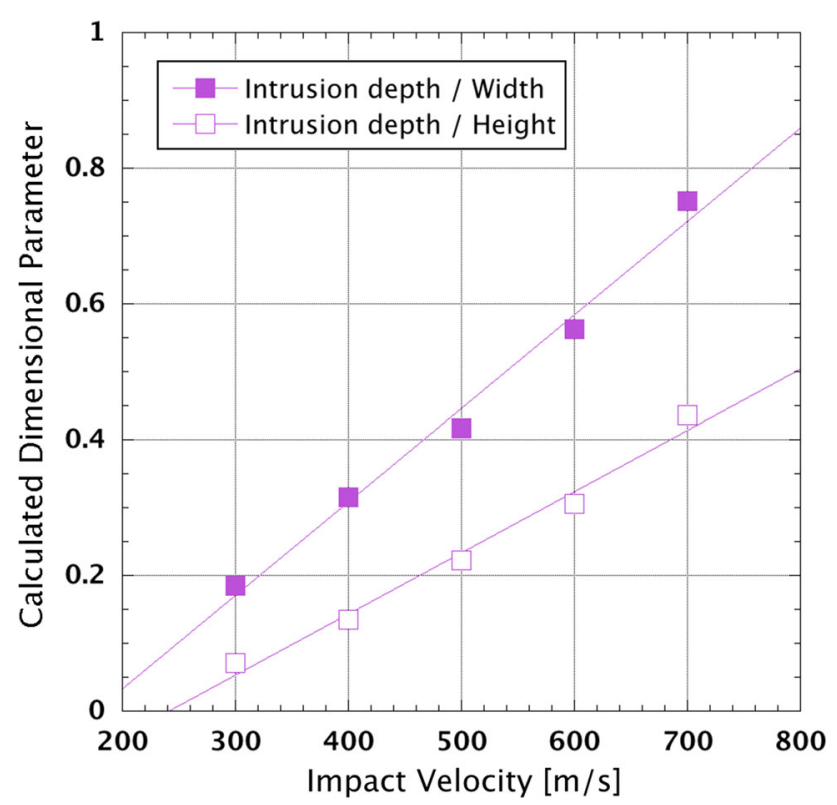

Fig. 11 Relationship between calculated dimensional parameters and impact velocity. These parameters were measured from calculation results of maximum deformation state of particles in various impact simulations

necessary and sufficient amount of newly formed surface of the substrate. The critical velocity is the minimum impact velocity that is required to obtain a sufficient deposition of particles. It should be noted that the threshold strain of the newly formed surface may depend on the material system and surface conditions.

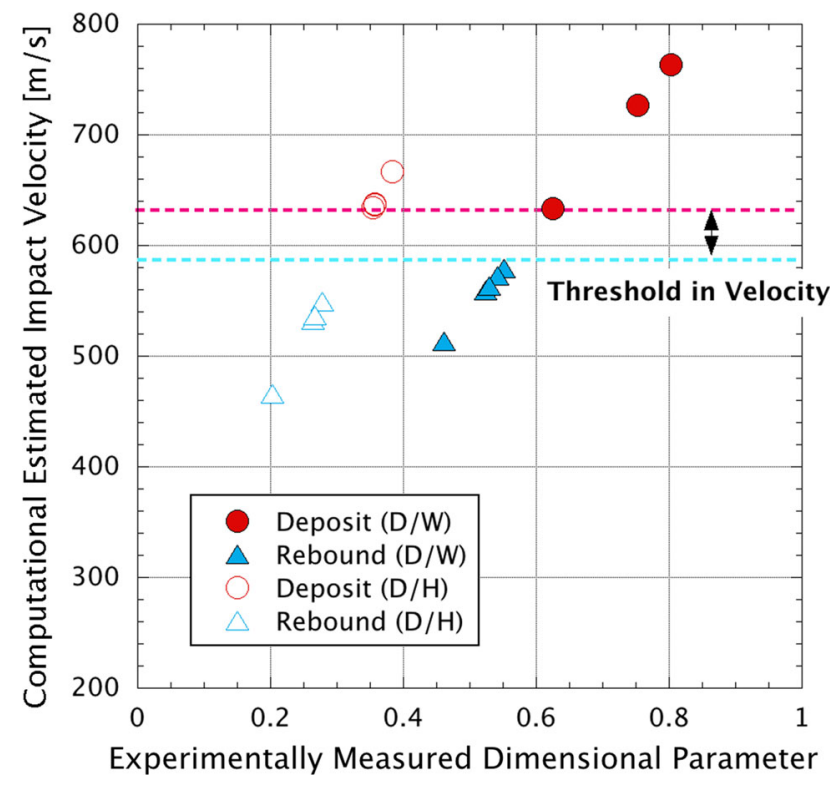

Fig. 12 Relationship between experimentally measured dimensional parameters and estimated impact velocity

Table 8 Threshold velocity estimated from the relationship in Fig. 11

\begin{tabular}{lcc}
\hline & Lower threshold $(\mathrm{m} / \mathrm{s})$ & Upper threshold $(\mathrm{m} / \mathrm{s})$ \\
\hline$V_{\mathrm{d} 25-\mathrm{DW}}$ & 549 & 633 \\
$V_{\mathrm{d} 25-\mathrm{DH}}$ & 576 & 629 \\
\hline
\end{tabular}
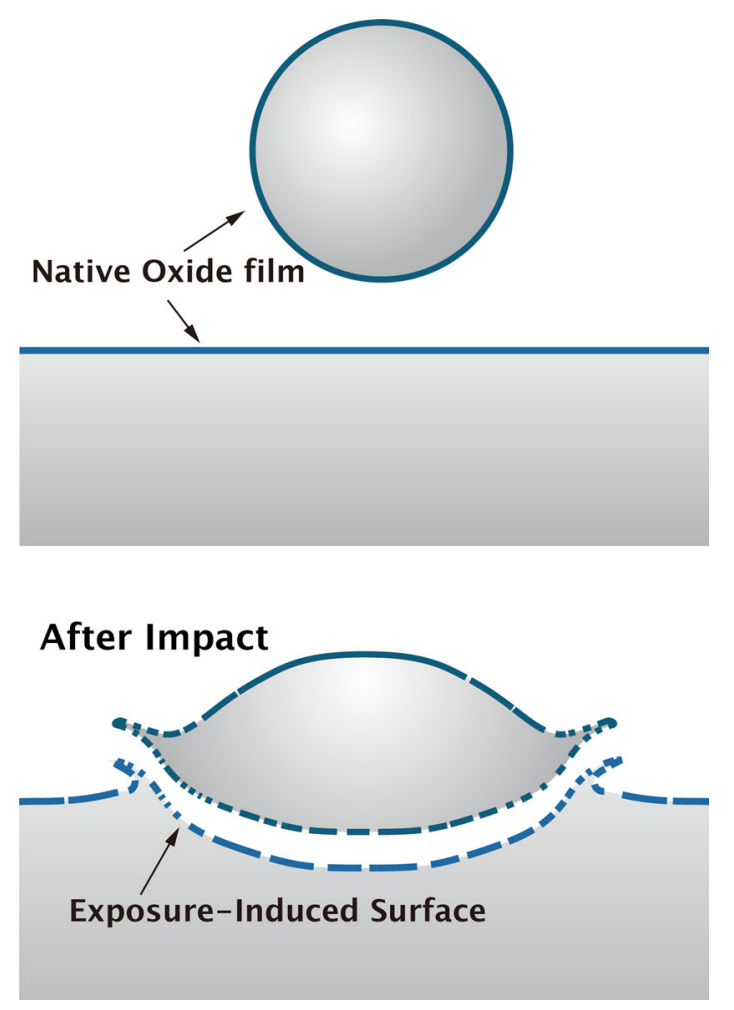

Fig. 13 Schematic model of new surface creation during impingement in cold spray process 


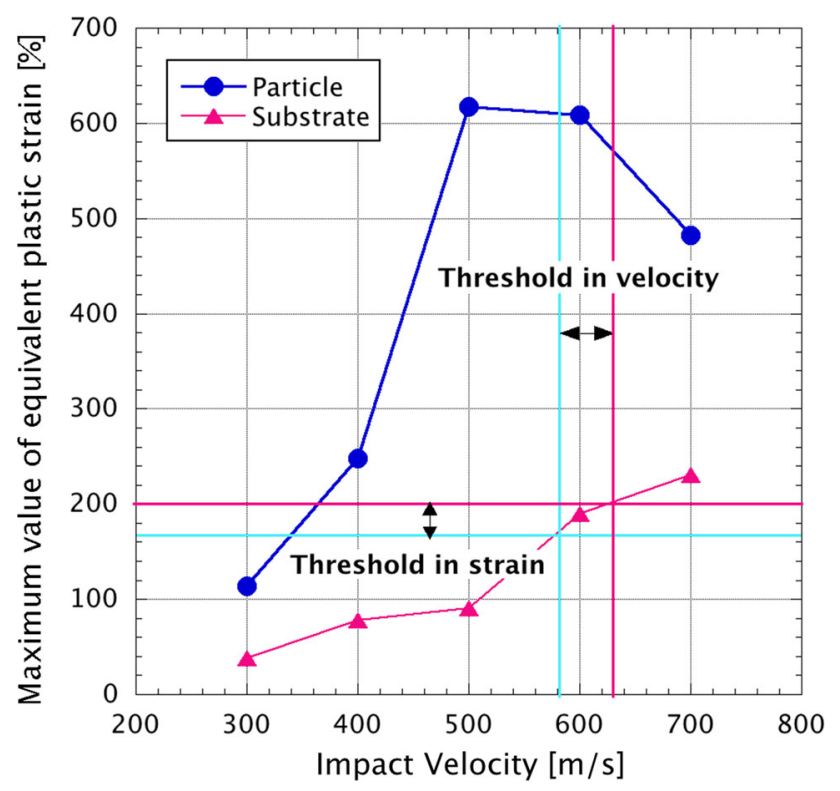

Fig. 14 Relationship between deposit threshold in velocity and strain assumed from the simulated strain change

\section{Conclusions}

In this study, in order to understand the deposition mechanism of cold-sprayed MCrAlY coating, the deformation behavior of cold-spray deposited particles was investigated by experimental and simulation approaches. An FIB system was used to fabricate deposited particle cross sections. SEM observations of the cross sections were used to determine the geometric characteristics of well-bonded particles. In the case of well-bonded particles, deep intrusion and large deformation were observed. The dimensional parameters were used to quantify the deposition threshold. From J-C FEM simulation results, there are direct correlations between the dimensional parameters and the impact velocity. Therefore, the dimensional parameters were used to predict the critical velocity. Detailed study of the FEM results revealed that the dominant factors are the equivalent plastic strain of the particle and the substrate, which occur during impact and deformation. The conditions required for particle deposition can be represented by the equivalent plastic strain - the critical amount of plastic strain to adhere the particle-substrate interface. Since the substrate is more difficult to deform than the particle, the critical condition is determined by the strain amount of the substrate. In the case of the material system of this study, the critical strain lies in the range of $175-200 \%$. The physical reason for this particular strain value is not well understood, but future research will include further investigation.

Acknowledgment This work was partly supported by JSPS KAKENHI Grant Number 15H05501.
Open Access This article is distributed under the terms of the Creative Commons Attribution 4.0 International License (http://crea tivecommons.org/licenses/by/4.0/), which permits unrestricted use, distribution, and reproduction in any medium, provided you give appropriate credit to the original author(s) and the source, provide a link to the Creative Commons license, and indicate if changes were made.

\section{References}

1. A.P. Alkhimov, V.F. Kosarev, and A.N. Papyrin, A Method of Cold Gas-Dynamic Deposition, Sov. Phys. Dokl., 1990, 35, p 1047-1049

2. A.P. Alkimov, V.F. Kosarev, N.I. Nesterovich, and A.N. Papyrin, Method of Applying Coatings, Russian Patent 1,618,778, 8 Sep 1990

3. A.P. Alkhimov, A.N. Papyrin, V.F. Kosarev, N.I. Nesterovich, and M.M. Shushpanov, Gas-Dynamic Spraying Method for Applying a Coating, U.S. Patent 5,302,414, 12 Apr 1994

4. A.P. Alkhimov, A.N. Papyrin, V.F. Kosarev, N.I. Nesterovich, and M.M. Shushpanov, Method and Device for Coating, European Patent 0,484,533 B1, 25 Jan 1995

5. F. Leonardi, J.M. Ginder, and R.C. McCune, Method of Manufacturing Electromagnetic Devices Using Kinetic Spray, U.S. Patent 6,592,935, 15 Jul 2003

6. A.N. Papyrin, Cold Spray Technology, Adv. Mater. Process., 2001, 159(9), p 49-51

7. M.R. Dorfman, M. Nonni, J. Mallon, W. Woodard, and P. Meyer, Thermal Spray Technology Growth in Gas Turbine Coatings, Thermal Spray 2004: Advances in Technology and Application, Vol 1129, May 10-12, 2004 (Osaka, Japan), ASM International, 2004, p 90-95

8. D.R.G. Achar, R. Munoz-Arroyo, L. Singheiser, and W.J. Quadakkers, Modelling of Phase Equilibria in MCrAlY Coating Systems, Surf. Coat. Technol., 2004, 187(2-3), p 272-283

9. T. Stoltenhoff, H. Kreye, and H.J. Richter, An Analysis of the Cold Spray Process and its Coatings, J. Therm. Spray Technol., 2002, 11(4), p 542-550

10. J. Karthikeyan and C.M. Kay, Cold Spray Technology: An Industrial Perspective, Thermal Spray 2003: Advancing the Science and Applying the Technology, B.R. Marple, and C. Moreau, Eds., May 5-8, 2003 (Orlando, FL), ASM International, 2003, p $117-121$

11. Y. Ichikawa, K. Ogawa, and I. Nonaka, High-Temperature Oxidation Behavior of Cold-Sprayed MCrAlY Coatings, J. Soc. Mater. Sci. Jpn., 2011, 60(2), p 159-166

12. Y. Ichikawa, K. Sakaguchi, K. Ogawa, T. Shoji, S. Barradas, M. Jeandin, and M. Boustie, Deposition Mechanisms of Cold Gas Dynamic Sprayed MCrAlY Coatings, Thermal Spray 2007: Global Coating Solutions, Vol 1212, B.R. Marple, M.M. Hyland, Y.-C. Lau, C.-J. Li, R.S. Lima, and G. Montavon, Eds., May 14-16, 2007 (Beijing, China), ASM International, 2007, p 54-59

13. Y. Ichikawa, Y. Watanabe, I. Nonaka, and H. Miura, Microstructure Evaluation of Cold-Sprayed Copper Coatings by EBSD, J. Spray Coat. Soc. Jpn., 2013, 50, p 170-175

14. Y. Ichikawa and K. Ogawa, Effect of Substrate Surface Oxide Film Thickness on Deposition Behavior and Deposition Efficiency in the Cold Spray Process, J. Therm. Spray Technol., 2015, 24(7), p 1269-1276

15. R.C. Dykhuizen, M.F. Smith, D.L. Gilmore, R.A. Neiser, X. Jiang, and S. Sampath, Impact of High Velocity Cold Spray Particles, J. Therm. Spray Technol., 1999, 8(4), p 559-564 
16. D.L. Gilmore, R.C. Dykhuizen, R.A. Neiser, M.F. Smith, and T.J. Romer, Particle Velocity and Deposition Efficiency in Cold Spray Process, J. Therm. Spray Technol., 1999, 8(4), p 576-582

17. M. Grujicic, J.R. Saylor, D.E. Beasley, W.S. DeRosset, and D. Helfritch, Computational Analysis of the Interfacial Bonding Between Feed-Powder Particles and the Substrate in the ColdGas Dynamic-Spray Process, Appl. Surf. Sci., 2003, 219, p 211227

18. H. Assadi, F. Gärtner, T. Stoltenhoff, and H. Kreye, Bonding Mechanism in Cold Gas Spraying, Acta Mater., 2003, 51(15), p 4379-4394

19. F.A. Stevie, T.C. Shane, P.M. Kahora, R. Hull, D. Bahnck, V.C. Kannan, and E. David, Applications of Focused Ion Beams in Microelectronics Production, Design and Development, Surf. Interface Anal., 1995, 23(2), p 61-68

20. H. Bender, Focused Ion Beam and Transmission Electron Microscopy for Process Development, Analytical and Diagnostic Techniques for Semiconductor Materials, Devices, and Processes, B.O. Kolbeson, C. Claeys, P. Stallhofer, F. Tardif, J. Benton, T. Shaffner, D. Schroder, S. Kishino, and P. RaiChoudhury, Eds., Sep 13-17, 1999 (Leuven, Belgium), The Electrochemical Society PV 99-16, 1999, p 232-247

21. K. Yokoyama, M. Watanabe, S. Kuroda, Y. Gotoh, T. Schmidt, and F. Gärtner, Simulation of Solid Particle Impact Behavior for Spray Processes, Mater. Trans., 2006, 47(7), p 1697-1702

22. T. Schmidt, F. Gärtner, H. Assadi, and H. Kreye, Development of a Generalized Parameter Window for Cold Spray Deposition, Acta Mater., 2006, 54(3), p 729-742

23. M. Grujicic, C.L. Zhao, W.S. DeRosset, and D. Helfritch, Adiabatic Shear Instability Based Mechanism for Particles/Substrate Bonding in the Cold-Gas Dynamic-Spray Process, Mater. Des., 2004, 25(8), p 681-688
24. W.-Y. Li, H. Liao, C.-J. Li, H.-S. Bang, and C. Coddet, Numerical Simulation of Deformation Behavior of Al Particles Impacting on Al Substrate and Effect of Surface Oxide Films on Interfacial Bonding in Cold Spraying, Appl. Surf. Sci., 2007, 253(11), p 5084-5091

25. G.R. Johnson and W.H. Cook, Fracture Characteristics of Three Metals Subjected to Various Strains, Strain Rates, Temperatures and Pressures, Eng. Fract. Mech., 1985, 21(1), p 31-48

26. G.R. Johnson and W.H. Cook, A Constitutive Model and Data for Metals Subjected to Large Strains, High Rates and High Temperatures, Proceedings of the Seventh International Symposium on Ballistics, Apr 19-21, 1983 (the Hague, the Netherlands), Royal Institution of Engineers in the Netherlands (KIvI), Division for Military Engineering in Co-operation with the American Defense Preparedness Association, 1983, p 541-547

27. G.R. Johnson and T.J. Holmquist, Evaluation of Cylinder-Impact Test Data for Constitutive Model Constants, J. Appl. Phys. (Melville, NY, U.S.), 1988, 64(8), p 3901-3910

28. R. Sievert, H.-D. Noack, A. Hamann, P. Löwe, K.N. Singh, G. Künecke, R. Clos, U. Schreppel, P. Veit, E. Uhlmann, and R. Zettier, Simulation der Spansegmentierung beim Hochgeschwindigkeits-Zerspanen unter Berucksichtigung duktiler Schädigung (Simulation of Chip Segmentation During High-Speed Machining Considering Ductile Damage), Technische Mechanik, 2003, 23(2-4), p 216-233 (in German)

29. J.M. Pereira and B.A. Lerch, Effects of Heat Treatment on the Ballistic Impact Properties of Inconel 718 for Jet Engine Fan Containment Applications, Int. J. Impact Eng., 2001, 25(8), p 715-733

30. H. Takagi, K. Kikuchi, R. Maeda, T.R. Chung, and T. Suga, Surface Activated Bonding of Silicon Wafers at Room Temperature, Appl. Phys. Lett., 1996, 68(16), p 2222-2224 